University of Nebraska - Lincoln

DigitalCommons@University of Nebraska - Lincoln

Faculty Publications from the Department of Electrical \& Computer Engineering, Department Electrical and Computer Engineering

2009

\title{
Dynamic Modeling and Control of Doubly Fed Induction Generators Driven by Wind Turbines
}

Wei Qiao

University of Nebraska-Lincoln, wqiao@engr.unl.edu

Follow this and additional works at: https://digitalcommons.unl.edu/electricalengineeringfacpub

Part of the Electrical and Computer Engineering Commons

Qiao, Wei, "Dynamic Modeling and Control of Doubly Fed Induction Generators Driven by Wind Turbines" (2009). Faculty Publications from the Department of Electrical and Computer Engineering. 140.

https://digitalcommons.unl.edu/electricalengineeringfacpub/140

This Article is brought to you for free and open access by the Electrical \& Computer Engineering, Department of at DigitalCommons@University of Nebraska - Lincoln. It has been accepted for inclusion in Faculty Publications from the Department of Electrical and Computer Engineering by an authorized administrator of DigitalCommons@University of Nebraska - Lincoln. 


\title{
Dynamic Modeling and Control of Doubly Fed Induction Generators Driven by Wind Turbines
}

\author{
Wei Qiao, Member, IEEE
}

\begin{abstract}
Two different models are presented and developed in PSCAD/EMTDC to represent a variable-speed wind turbine equipped with a doubly fed induction generator (DFIG). One is the most detailed switching-level (SL) model. The other is a simplified fundamental-frequency (FF) model. The effect of different shaft system representations on the dynamic behavior of the wind turbine generator (WTG) system and the issue of damping low-frequency torsional oscillations are investigated. Dynamic and transient simulation studies are carried out to compare two models with different shaft system representations. Results show that the FF model is sufficient while the lumpedmass shaft model is insufficient to represent the dynamic behavior of the WTG. The FF model with the two-mass shaft representation is therefore recommended to represent the DFIG wind turbines for power system dynamic and transient studies.
\end{abstract}

Index Terms--Doubly fed induction generator, dynamic model, fundamental-frequency model, shaft system, switching-level model, torsional oscillation, wind turbine

\section{INTRODUCTION}

$\mathrm{W}$ ORLDWIDE concern about the environmental pollution and a possible energy crisis has led to increasing interest in technologies for generation of clean and renewable electrical energy. Among various renewable energy sources, wind power is the most rapidly growing one.

During the last decade, the concept of a variable-speed wind turbine equipped with a doubly fed induction generator (DFIG) has received increasing attention due to its noticeable advantages over other wind turbine generator (WTG) concepts [1]-[4]. In the DFIG concept, the induction generator is grid-connected at the stator terminals, but the rotor terminals are connected to the grid via a partial-load variable frequency AC/DC/AC converter (VFC). The VFC only needs to handle a fraction (25-30\%) of the total power to achieve full control of the generator.

Much research effort has gone into modeling the DFIG wind turbines and studying their impact on the dynamic performance of the power system [2]-[10]. In these works, the power electronic converter models are simplified as controlled ideal voltage-sources or current-sources. This permits large integration time-steps during transient simulations, which is essential in the representation of large networks. However, in the DFIG wind turbine system, the VFC and its power electronics (IGBT-switches) are the most sensitive part to grid

W. Qiao is with the Department of Electrical Engineering, University of Nebraska - Lincoln, Lincoln, NE 68588-0511 USA (e-mail: weiqiao@ieee.org). disturbances. The converter action might determine the operation of the WTG during the transient disturbances in the power grid [2]. A question that arises is whether the simplified models of the VFC adequately represent its behavior during transient conditions.

At the most detailed level, the operation of individual IGBT switches is fully represented [11]. This level of modeling is useful for the detailed study of the power converter and its control strategy, and confirming the results of various simplified models. However, since the IGBT components in the VFC are switched on and off at a high frequency (several $\mathrm{kHz}$ or higher), it requires a very small simulation time-step (typically $10-50 \mu \mathrm{s}$ ) to accurately represent the PWM waveforms. This detailed switching-level (SL) model uses excessive computation time and is unsuitable for dynamic and transient study of large power systems with a high-level penetration of DFIG wind turbines.

This paper presents two different models developed in PSCAD/EMTDC to represent a DFIG wind turbine. One is a detailed SL model, in which the VFC is fully represented by individual IGBT switches with a dc-link capacitor. The other is a simplified fundamental-frequency (FF) model, in which the VFC is represented by two current-controlled voltage sources but takes into account the dc-link dynamics. The other parts of the WTG system, including the wind turbine, shaft system, induction generator, and control system, are modeled or designed with the same level of detail for both the SL and FF models. The effect of different shaft system representations and the issue of damping low-frequency torsional oscillations are also investigated. Simulation studies are carried out for a 3.6 MW DFIG wind turbine to compare the two models with different shaft system representations.

\section{WIND TURBINE AND DFIG MODEL}

The basic configuration of a DFIG wind turbine is shown in Fig. 1. The wind turbine is connected to the induction generator through a mechanical shaft system, which consists of a low-speed shaft and a high-speed shaft and a gearbox in between. The wound-rotor induction generator in this configuration is fed from both stator and rotor sides. The stator is directly connected to the grid while the rotor is fed through a VFC. In order to produce electrical power at constant voltage and frequency to the utility grid over a wide operating range from subsynchronous to supersynchronous speeds, the power flow between the rotor circuit and the grid 
must be controlled both in magnitude and in direction. Therefore, the VFC consists of two four-quadrant IGBT PWM converters (a rotor-side converter RSC and a grid-side converter GSC) connected back-to-back by a dc-link capacitor. The crow-bar circuit is used to short-circuit the RSC in order to protect it from over-current in the rotor circuit during transient disturbances.

The operation of the DFIG wind turbine is regulated by a control system, which generally consists of two parts: the electrical control of the DFIG and the mechanical control of the wind turbine blade pitch angle. Control of the DFIG is achieved by controlling the VFC, which includes control of the RSC and control of the GSC, as shown in Fig. 1.

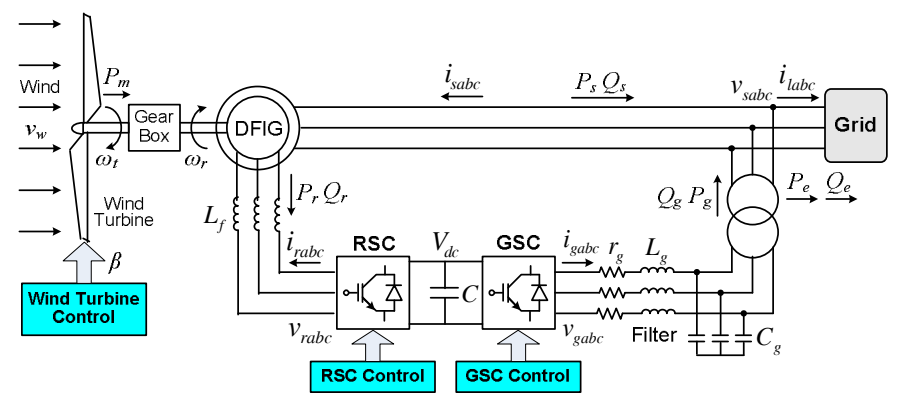

Fig. 1. Configuration of a DFIG wind turbine connected to a utility grid.

\section{A. Modeling of the Wind Turbine Aerodynamics}

The aerodynamic model of a wind turbine can be characterized by the well-known $C_{P}-\lambda-\beta$ curves. $C_{P}$ is the power coefficient, which is a function of both tip-speed-ratio $\lambda$ and the blade pitch angle $\beta$. The tip-speed-ratio $\lambda$ is defined by

$$
\lambda=\frac{\omega_{t} R}{v_{w}}
$$

where $R$ is the blade length in $\mathrm{m}, \omega_{t}$ is the wind turbine rotational speed in $\mathrm{rad} / \mathrm{s}$, and $v_{w}$ is the wind speed in $\mathrm{m} / \mathrm{s}$, and the numerator $\left(\omega_{t} R\right)$ represents the blade tip speed in $\mathrm{m} / \mathrm{s}$ of the wind turbine. The $C_{P-\lambda}-\beta$ curves depend on the blade design and are given by the wind turbine manufacturer. In this paper, the mathematical representation of the $C_{P}$ curves used for the 3.6 MW wind turbine is obtained by curve fitting, given by [12],

$$
C_{P}(\beta, \lambda)=\sum_{i=0}^{4} \sum_{j=0}^{4} \alpha_{i j} \beta^{i} \lambda^{j}
$$

where the coefficients $\alpha_{i j}$ are given in Table 4-7 of [12].

Given the power coefficient $C_{P}$, the mechanical power that the wind turbine extracts from the wind is calculated by [2]:

$$
P_{m}=\frac{1}{2} \rho A_{r} v_{w}^{3} C_{P}(\lambda, \beta)
$$

Where $\rho$ is the air density in $\mathrm{kg} / \mathrm{m}^{3}, A_{r}=\pi R^{2}$ is the area in $\mathrm{m}^{2}$ swept by the rotor blades. At a certain wind speed, there is a unique wind turbine rotational speed to achieve the maximum power coefficient, $C_{P m}$, and thereby the maximum mechanical (wind) power. If the wind speed is below the rated value, the wind turbine operates in the variable speed mode, and the rotational speed is adjusted (by DFIG speed control or active power control) such that $C_{P}$ remains at the $C_{P m}$ point. In this operating mode, the wind turbine pitch control is deactivated and the pitch angle $\beta$ is fixed. However, if the wind speed increases above the rated value, the pitch control is activated to increase the wind turbine pitch angle to reduce the mechanical power extracted from the wind.

The wind turbine aerodynamic model is represented by a custom component in PSCAD/EMTDC.

\section{B. Modeling of the Shaft System}

The shaft system of the WTG can be represented either by a two-mass system or by a single lumped-mass system [2], [12], [13]. In the two-mass model, separate masses are used to represent the low-speed turbine and the high-speed generator, and the connecting resilient shaft is modeled as a spring and a damper, as shown in Fig. 2. The electromechanical dynamic equations are then given by

$$
\begin{aligned}
& 2 H_{t} p \omega_{t}=T_{m}-D_{t} \omega_{t}-D_{t g}\left(\omega_{t}-\omega_{r}\right)-T_{t g} \\
& 2 H_{g} p \omega_{r}=T_{t g}+D_{t g}\left(\omega_{t}-\omega_{r}\right)-D_{g} \omega_{r}-T_{e} \\
& p T_{t g}=K_{t g}\left(\omega_{t}-\omega_{r}\right)
\end{aligned}
$$

where $p=d / d t ; \omega_{t}$ and $\omega_{r}$ are the turbine and generator rotor speed, respectively; $T_{m}$ and $T_{e}$ are the mechanical torque applied to the turbine and the electrical torque of the generator, respectively; $T_{t g}$ is an internal torque of the model; $H_{t}$ and $H_{g}$ are the inertia constants of the turbine and the generator, respectively; $D_{t}$ and $D_{g}$ are the damping coefficients of the turbine and the generator, respectively; $D_{t g}$ is the damping coefficient of the flexible coupling (shaft) between the two masses; $K_{t g}$ is the shaft stiffness. In Fig. 2, $N_{t} / N_{g}$ is the gear ratio of the gearbox. The standard multi-mass component model in the PSCAD/EMTDC library is used to model the two-mass system.

As in [3], [5], [7], [10], the shaft system is simply modeled as a single lumped-mass system with the lumped inertia constant $H_{m}$, calculated by.

$$
H_{m}=H_{t}+H_{g}
$$

The electromechanical dynamic equation is then given by

$$
2 H_{m} p \omega_{m}=T_{m}-T_{e}-D_{m} \omega_{m}
$$

where $\omega_{m}$ is the rotational speed of the lumped-mass system and $\omega_{m}=\omega_{t}=\omega_{r}, D_{m}$ is the damping of the lumped system.

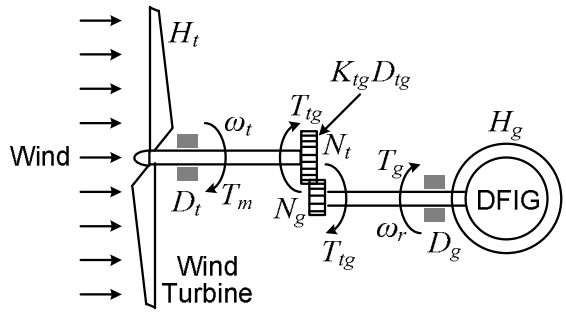

Fig. 2. DFIG wind turbine shaft system represented by a two-mass model.

\section{Modeling of the Induction Generator}

The induction generator in this study is a single-cage wound rotor induction machine. In terms of the instantaneous variables shown in Fig. 1, the stator and rotor equations can be written as follows in matrix form

$$
\begin{aligned}
& v_{s a b c}=r_{s} i_{s a b c}+p \lambda_{s a b c} \\
& v_{r a b c}=r_{r} i_{r a b c}+p \lambda_{r a b c}
\end{aligned}
$$

Applying synchronously rotating reference frame transformation [14] to (9) and (10), the voltage equations become 


$$
\begin{aligned}
& v_{d s}=r_{s} i_{d s}-\omega_{s} \lambda_{q s}+p \lambda_{d s} \\
& v_{q s}=r_{s} i_{q s}+\omega_{s} \lambda_{d s}+p \lambda_{q s} \\
& v_{d r}=r_{r} i_{d r}-\left(\omega_{s}-\omega_{r}\right) \lambda_{q r}+p \lambda_{d r} \\
& v_{q r}=r_{r} i_{q r}+\left(\omega_{s}-\omega_{r}\right) \lambda_{d r}+p \lambda_{q r}
\end{aligned}
$$

where $\omega_{s}$ is the rotational speed of the synchronous reference frame, $\omega_{r}$ is the rotor speed, and the flux linkages are given by

$$
\begin{aligned}
& \lambda_{d s}=L_{l s} i_{d s}+L_{m}\left(i_{d s}+i_{d r}\right)=L_{s} i_{d s}+L_{m} i_{d r} \\
& \lambda_{q s}=L_{l s} i_{q s}+L_{m}\left(i_{q s}+i_{q r}\right)=L_{s} i_{q s}+L_{m} i_{q r} \\
& \lambda_{d r}=L_{l r} i_{d r}+L_{m}\left(i_{d s}+i_{d r}\right)=L_{m} i_{d s}+L_{r} i_{d r} \\
& \lambda_{q r}=L_{l r} i_{q r}+L_{m}\left(i_{q s}+i_{q r}\right)=L_{m} i_{q s}+L_{r} i_{q r}
\end{aligned}
$$

where $L_{s}=L_{l s}+L_{m}, L_{r}=L_{l r}+L_{m} ; L_{l s}, L_{l r}$ and $L_{m}$ are the stator leakage, rotor leakage and mutual inductances, respectively.

In order for the rotor mmf to be in synchronism with the stator mmf, the frequency of the rotor current, $\omega_{r f}$, must satisfy the slip frequency constraint

$$
\omega_{r f}=\omega_{s}-\omega_{r}=s \omega_{s}
$$

The per-unit electromagnetic torque equation is given by

$$
T_{e}=\lambda_{d s} i_{q s}-\lambda_{q s} i_{d s}=\lambda_{q r} i_{d r}-\lambda_{d r} i_{q r}=L_{m}\left(i_{q s} i_{d r}-i_{d s} i_{q r}\right)
$$

Neglecting the power losses associated with the stator and rotor resistances, the active and reactive stator powers are:

$$
\begin{aligned}
& P_{s}=\frac{3}{2}\left(v_{d s} i_{d s}+v_{q s} i_{q s}\right) \\
& Q_{s}=\frac{3}{2}\left(v_{q s} i_{d s}-v_{d s} i_{q s}\right)
\end{aligned}
$$

and the active and reactive rotor powers are given by

$$
\begin{aligned}
& P_{r}=\frac{3}{2}\left(v_{d r} i_{d r}+v_{q r} i_{q r}\right) \\
& Q_{r}=\frac{3}{2}\left(v_{q r} i_{d r}-v_{d r} i_{q r}\right)
\end{aligned}
$$

The PSCAD/EMTDC software library provides the standard model of the wound rotor induction machine, which is used in this study.

\section{Modeling of the Variable-Frequency Converter}

Two different models are used to represent the dynamics of the VFC, one is a detailed SL model and the other is a simplified FF model.

1) SL Model: The VFC is represented by two four-quadrant IGBT PWM converters connected back-to-back by a dc-link capacitor. Both converters are fully represented by individual IGBT switches and the switching frequency is $2 \mathrm{kHz}$, as shown in Fig. 1. The IGBT switches, dc-link capacitor, and other components of the VFC are built from the standard component models from the PSCAD/EMTDC library

2) FF Model: The VFC is simply represented by two current-controlled voltage sources which take into account the dc-link dynamics, as shown in Fig. 3. The RSC injects the current $i_{1}=P_{r} / v_{d c}$ into the dc-link, while the GSC injects $i_{2}=$ $P_{g} / v_{d c}$ into the dc-link. Neglecting the switching and conduction losses in the converters and the power losses in the dc-link, the dc-link dynamics are given by

$$
i_{d c}=i_{1}-i_{2}=C p v_{d c}
$$

At steady state, $P_{r}=P_{g}$ and $i_{1}=i_{2}$, thereby the dc-link voltage, $v_{d c}$, is constant. However, when a disturbance occurs, the relationship, $P_{r}=P_{g}$, is broken; and the current flowing through the dc-link capacitor, $i_{d c}=i_{1}-i_{2} \neq 0$, which results in fluctuations of the dc-link voltage $v_{d c}$.

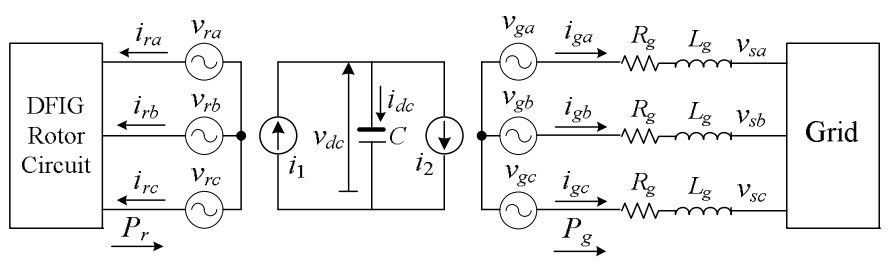

Fig. 3. FF model of the VFC.

\section{Design Of The Control System}

The objective of the RSC is to govern both the stator-side active and reactive powers independently; while the objective of the GSC is to keep the dc-link voltage constant regardless of the magnitude and direction of the rotor power. The GSC control scheme can also be designed to regulate the reactive power. The reactive power control by the RSC and GSC is necessary to keep the voltage within the desired range, when the DFIG feeds into a weak power system with insufficient local reactive compensation. The wind turbine controller controls the pitch angle of the blades, which determine the mechanical power that the turbine extracts from the wind.

\section{A. Design of the RSC Controllers}

The RSC control scheme consists of two cascaded control loops. The inner current control loops regulate independently the $d$-axis and $q$-axis rotor current components, $i_{d r}$ and $i_{q r}$, according to some synchronously rotating reference frame. The stator-flux oriented reference frame [14] is the most commonly used one. The outer control loops regulate both the stator active power (or the generator rotor speed) and reactive power independently.

In the stator-flux oriented reference frame, the $d$-axis is aligned with the stator flux linkage vector $\lambda_{s}$, namely, $\lambda_{d s}=\lambda_{s}$ and $\lambda_{q s}=0$. This gives the following relationships

$$
\begin{gathered}
i_{q s}=-L_{m} i_{q r} / L_{s} \\
i_{d s}=L_{m}\left(i_{m s}-i_{d r}\right) / L_{s} \\
P_{s}=-\frac{3}{2} \omega_{s} L_{m}^{2} i_{m s} i_{q r} / L_{s} \\
Q_{s}=\frac{3}{2} \omega_{s} L_{m}^{2} i_{m s}\left(i_{m s}-i_{d r}\right) / L_{s} \\
v_{d r}=r_{r} i_{d r}+\sigma L_{r} p i_{d r}-s \omega_{s} \sigma L_{r} i_{q r} \\
v_{q r}=r_{r} i_{q r}+\sigma L_{r} p i_{q r}+s \omega_{s}\left(\sigma L_{r} i_{d r}+L_{m}^{2} i_{m s} / L_{s}\right)
\end{gathered}
$$

where

$$
\begin{aligned}
& i_{m s}=\frac{v_{q s}-r_{s} i_{q s}}{\omega_{s} L_{m}} \\
& \sigma=1-\frac{L_{m}^{2}}{L_{s} L_{r}}
\end{aligned}
$$

Equations (28) and (29) indicate that $P_{s}$ and $Q_{s}$ can be controlled independently by regulating the rotor current components, $i_{q r}$ and $i_{d r}$, respectively. Consequently, the reference values of $i_{d r}$ and $i_{q r}$ can be determined from the outer power control loops.

1) Design of the Inner Current Control Loops in Fig. 4: Let

$$
v_{d r 1}=r_{r} i_{d r}+\sigma L_{r} p i_{d r}
$$




$$
v_{q r 1}=r_{r} i_{q r}+\sigma L_{r} p i_{q r}
$$

representing parts of (30) and (31), then (34) and (35) can be rewritten into a matrix form as

$$
p\left[\begin{array}{l}
i_{d r} \\
i_{q r}
\end{array}\right]=-\frac{r_{r}}{\sigma L_{r}}\left[\begin{array}{cc}
1 & 0 \\
0 & 1
\end{array}\right] i_{d r}+\frac{1}{\sigma L_{r}}\left[\begin{array}{c}
v_{d r 1} \\
v_{q r 1}
\end{array}\right]
$$

Equation (36) indicates that $i_{d r}$ and $i_{q r}$ respond to $v_{d r 1}$ and $v_{q r 1}$ respectively, through a first-order transfer function without cross-coupling. It is therefore possible to design the following feedback loops and PI controllers

$$
\begin{aligned}
& v_{d r 1}=\left(k_{p r}+\frac{k_{i r}}{s}\right)\left(i_{d r}^{*}-i_{d r}\right) \\
& v_{q r 1}=\left(k_{p r}+\frac{k_{i r}}{s}\right)\left(i_{q r}^{*}-i_{q r}\right)
\end{aligned}
$$

Substituting (37) and (38) into (30) and (31) gives

$$
\begin{aligned}
& v_{d r}=\left(k_{p r}+\frac{k_{i r}}{s}\right)\left(i_{d r}^{*}-i_{d r}\right)-s \omega_{s} \sigma L_{r} i_{q r} \\
& v_{q r}=\left(k_{p r}+\frac{k_{i r}}{s}\right)\left(i_{q r}^{*}-i_{q r}\right)+s \omega_{s}\left(\sigma L_{r} i_{d r}+\frac{L_{m}^{2}}{L_{s}} i_{m s}\right)
\end{aligned}
$$

2) Design of the Speed Controller: The shaft system model has a significant impact on the dynamic behavior of the WTG and the design of the speed controller. In terms of (4)-(6), the transfer function from the EM torque, $T_{e}$, to rotor speed, $\omega_{r}$, for the two-mass shaft system (with $D_{t}=D_{g}=0$ ) is given by

$$
\frac{\omega_{r}}{T_{e}}=\frac{1}{2\left(H_{t}+H_{g}\right)} \frac{1}{s} \frac{2 H_{t} s^{2}+D_{t g} s+K_{t g}}{\frac{2 H_{t} H_{g}}{H_{t}+H_{g}} s^{2}+D_{t g} s+K_{t g}}
$$

which can be viewed as a lumped-mass system, 1/[2( $\left.\left.H_{t}+H_{g}\right) s\right]$, on the left and a bi-quadratic function on the right. PI controllers are normally designed to control the lumped-mass system. The bi-quadratic function causes instability by altering the phase and gain of the lumped-mass system [15]. On most practical machines, the damping coefficient, $D_{t g}$, is small so that both the numerator and denominator of the biquadratic function exhibit lightly damped torsional oscillation modes, if no specifically designed damping control is present in the WTG control system. The frequencies of these torsional oscillation modes are given by:

$$
\omega_{1}=\sqrt{\frac{K_{t g}}{2 H_{t}}}, \quad \omega_{2}=\sqrt{\frac{K_{t g}}{2 H_{t} H_{g} /\left(H_{t}+H_{g}\right)}}
$$

where $\omega_{1}<\omega_{2}$. The value of $\omega_{1}$ is typically less than several $\mathrm{Hz}$ on most practical WTG system. In order to improve the damping of the low-frequency torsional oscillations of the two-mass system, the speed controller has to be designed so that the closed-loop system has a sufficiently low bandwidth less than $\omega_{1}$. The speed controller acts as a low-pass filter to reduce the gains at oscillating frequencies.

For the lumped-mass model, the transfer function from $T_{e}$ to $\omega_{m}$, according to (8) (with $D_{m}=0$ ), is given by

$$
\frac{\omega_{m}}{T_{e}}=\frac{1}{2 H_{m} s}
$$

which is the same as the lumped-mass part in (41). In such a model, there are no low-frequency oscillating components, and the speed controller therefore can be designed with a higher bandwidth. However, the lumped-mass model might be insufficient to represent the dynamic behavior of the WTG system. The effect of the shaft system model on the dynamic behavior of the WTG and the speed controller is further investigated by simulation studies in Section IV.

Fig. 4 shows the overall vector control scheme of the RSC. In the SL model, the compensated outputs of the two current controllers, $v_{d r}$ and $v_{q r}$, are used by the PWM module to generate the IGBT gate control signals to drive the IGBT converter. In the FF model, $v_{d r}$ and $v_{q r}$ are used to determine the RSC ac-side voltages $v_{r a}, v_{r b}$ and $v_{r c}$ (Fig. 3) directly by applying the inverse transformation of the stator-flux oriented synchronously rotating reference frame transformation.

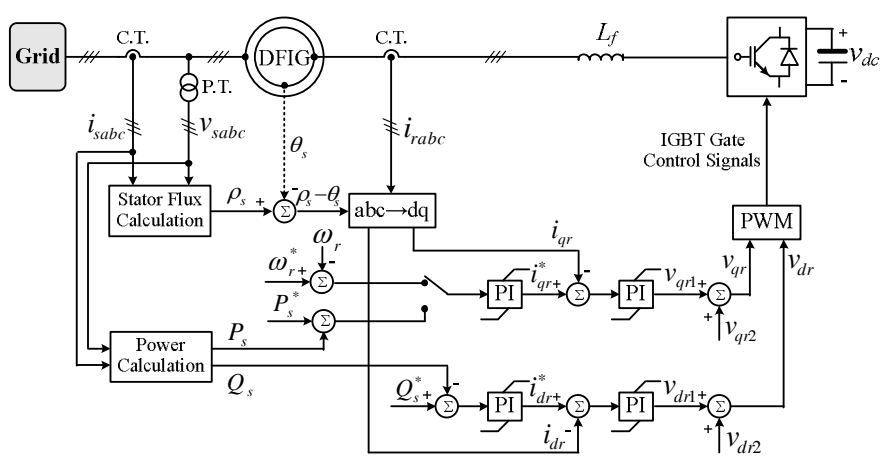

Fig. 4. Overall vector control scheme of the RSC. $v_{d r 2}=-s \omega_{s} \sigma L_{r} i_{q r}, v_{q r 2}=$ $s \omega_{s}\left(\sigma L_{r} i_{d r}+L_{m}{ }^{2} i_{m s} / L_{s}\right)$.

\section{B. Design of the GSC Controllers}

The GSC control scheme also consists of two cascaded control loops. The inner current control loops regulate independently the $d$-axis and $q$-axis GSC ac-side current components, $i_{d g}$ and $i_{q g}$, in the synchronously rotating reference frame. The outer control loops regulate the dc-link voltage and the reactive power exchanged between the GSC and the grid.

1) Design of the Inner Current Control Loops in Fig. 5: In Figs. 1 and 3, the ac-side circuit equations of the GSC can be written as

$$
p i_{g a b c}=-\frac{r_{g}}{L_{g}} i_{g a b c}+\frac{1}{L_{g}}\left(v_{g a b c}-v_{s a b c}\right)
$$

Applying the synchronously rotating reference frame transformation to (44) with the $d$-axis aligned to the grid voltage vector $v_{s}\left(v_{s}=v_{d s}, v_{q s}=0\right)$, the following $d$ - $q$ vector representation can be obtained for modeling the GSC ac-side

$$
\begin{aligned}
& v_{d g}=r_{g} i_{d g}+L_{g} p i_{d g}-\omega_{s} L_{g} i_{q g}+v_{s} \\
& v_{q g}=r_{g} i_{q g}+L_{g} p i_{q g}+\omega_{s} L_{g} i_{d g}
\end{aligned}
$$

Following the same procedure as in (34)-(38), $v_{d g}$ and $v_{q g}$ can be obtained by the following feedback loops and PI controllers

$$
v_{d g}=\left(k_{p g}+\frac{k_{i g}}{s}\right)\left(i_{d g}^{*}-i_{d g}\right)-\omega_{s} L_{g} i_{q g}+v_{s}
$$




$$
v_{q g}=\left(k_{p g}+\frac{k_{i g}}{s}\right)\left(i_{q g}^{*}-i_{q g}\right)+\omega_{s} L_{g} i_{d g}
$$

where the reference values $i_{d g}{ }^{*}$ and $i_{q g}{ }^{*}$ are obtained from the outer control loop.

2) Design of the Dc-link Voltage Controller: Neglecting harmonics due to switching and the losses in the GSC, the filtering inductor and the transformer (Figs. 1 and 3), the power balance equation is given by

$$
P_{r}-P_{g}=v_{d c} i_{d c}=C v_{d c} p v_{d c}
$$

Let

$$
v_{d c}=v_{d c 0}+\Delta v_{d c}
$$

where $v_{d c 0}\left(=v_{d c}{ }^{*}\right)$ is the dc component of $v_{d c}, \Delta v_{d c}$ is the ripple component of $v_{d c}$. Substituting (50) into (49) gives

$$
P_{r}-P_{g}=C v_{d c 0} p v_{d c}+C \Delta v_{d c} p v_{d c}
$$

Since $\Delta v_{d c} \ll v_{d c 0},(51)$ can be written as

$$
P_{r}-P_{g} \approx C v_{d c 0} p v_{d c}
$$

Therefore, the transfer function from $P_{g}$ to $v_{d c}$ is given by

$$
\frac{v_{d c}(s)}{P_{g}(s)}=\frac{1}{C v_{d c 0} s}
$$

Since

(53) becomes

$$
P_{g}=\frac{3}{2} v_{d s} i_{d g}=\frac{3}{2} v_{s} i_{d g}
$$

$$
\frac{v_{d c}(s)}{i_{d g}(s)}=\frac{\frac{3}{2} v_{s}}{C v_{d c 0} s}
$$

Therefore, it is possible to design a feedback loop and PI controller to generate the reference value of $i_{d g}$ as follows

$$
i_{d g}^{*}=\left(k_{p v}+\frac{k_{i v}}{s}\right)\left(v_{d c}^{*}-v_{d c}\right)
$$

3) Reactive Power Control: The reactive power exchanged between the GSC and the grid is given by

$$
Q_{g}=-\frac{3}{2} v_{d s} i_{q g}=-\frac{3}{2} v_{s} i_{q g}
$$

Therefore, the reference value of $i_{d g}$ can be determined directly from the reactive power command.

Fig. 5 shows the overall control scheme of the GSC.

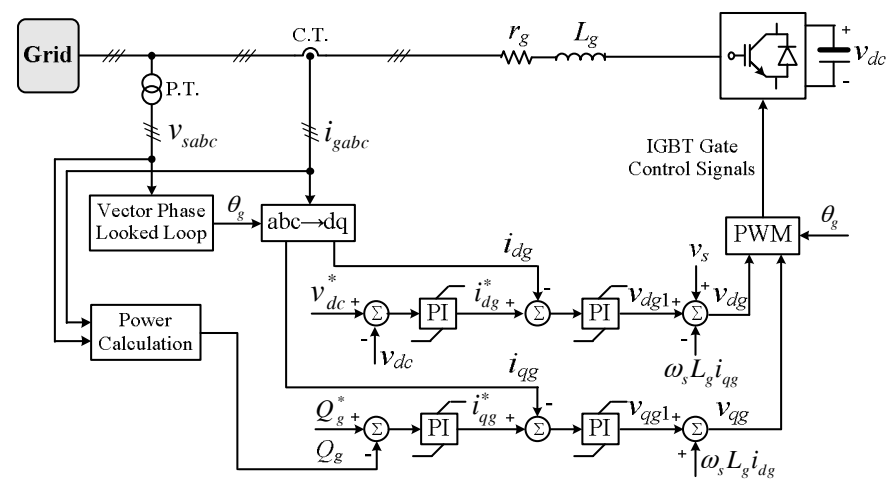

Fig. 5. Overall vector control scheme of the GSC.

\section{Design of the Pitch Angle $(\beta)$ Controller}

The pitch angle controller is only activated at high wind speeds. In such situations, the rotor speed can no longer be controlled within its limits by increasing the generated power, as this would lead to overloading of the generator and/or the converter. Therefore, the blade pitch angle is controlled to reduce the mechanical power that the wind turbine extracts from the wind as well as to prevent over-speeding of the WTG. Fig. 6 shows the structure of the pitch angle controller [11]. $P_{e}$ is the total output active power from the DFIG.

In this paper, all the PI controllers are equipped with the anti-windup design as discussed in [11].

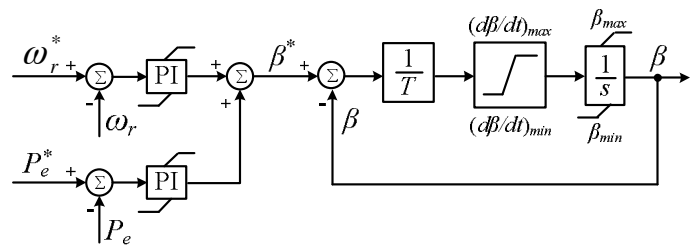

Fig. 6. Wind turbine pitch angle controller.

\section{Simulation Results}

To verify and compare the proposed models, a single machine infinite bus (SMIB) power system as shown in Fig. 7 is used for simulation studies in PSCAD/EMTDC. The WTG represents a 3.6 MW a DFIG wind turbine system [5], [11], [12]. It is connected to the grid through a step-up transformer and two parallel lines. A three-phase balanced electric load at the sending-end bus is modeled as a constant impedance load. The parameters of the DFIG wind turbine and the power network are given in the Appendix.

The wind turbine operates at a specific operating point with the wind speed $v_{w}=11.0 \mathrm{~m} / \mathrm{s}$, generator rotor speed $\omega_{r}=1.2$ pu, output active power $P_{t}=0.94 \mathrm{pu}$, and output reactive power $Q_{t}=0$. The RSC and GSC reactive power commands are set at $Q_{s}{ }^{*}=0$ and $Q_{g}{ }^{*}=0$, respectively. The speed control instead of the active power is applied to the RSC. If not specified, the two-mass model is used to represent the WTG shaft system.

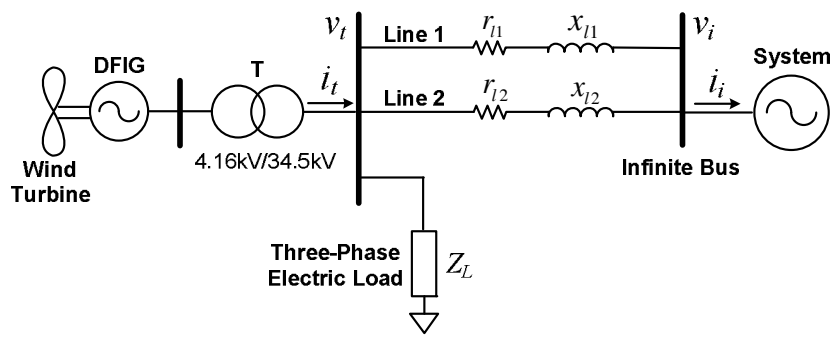

Fig. 7. A DFIG wind turbine connected to a SMIB power system.

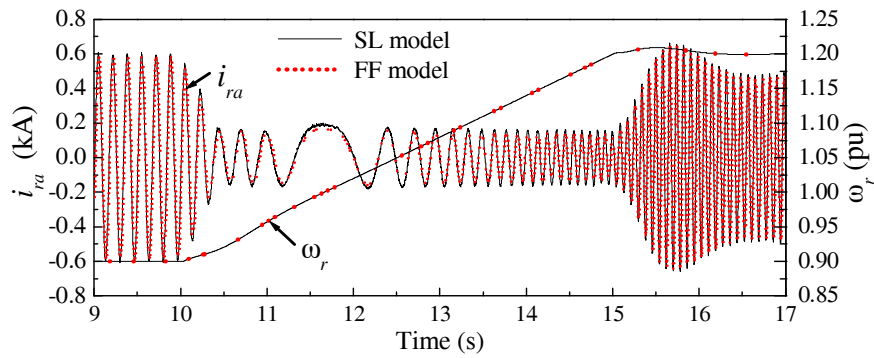

Fig. 8. DFIG acceleration through synchronous speed: DFIG rotor speed $\omega_{r}$ and rotor phase current $i_{r a}$ 

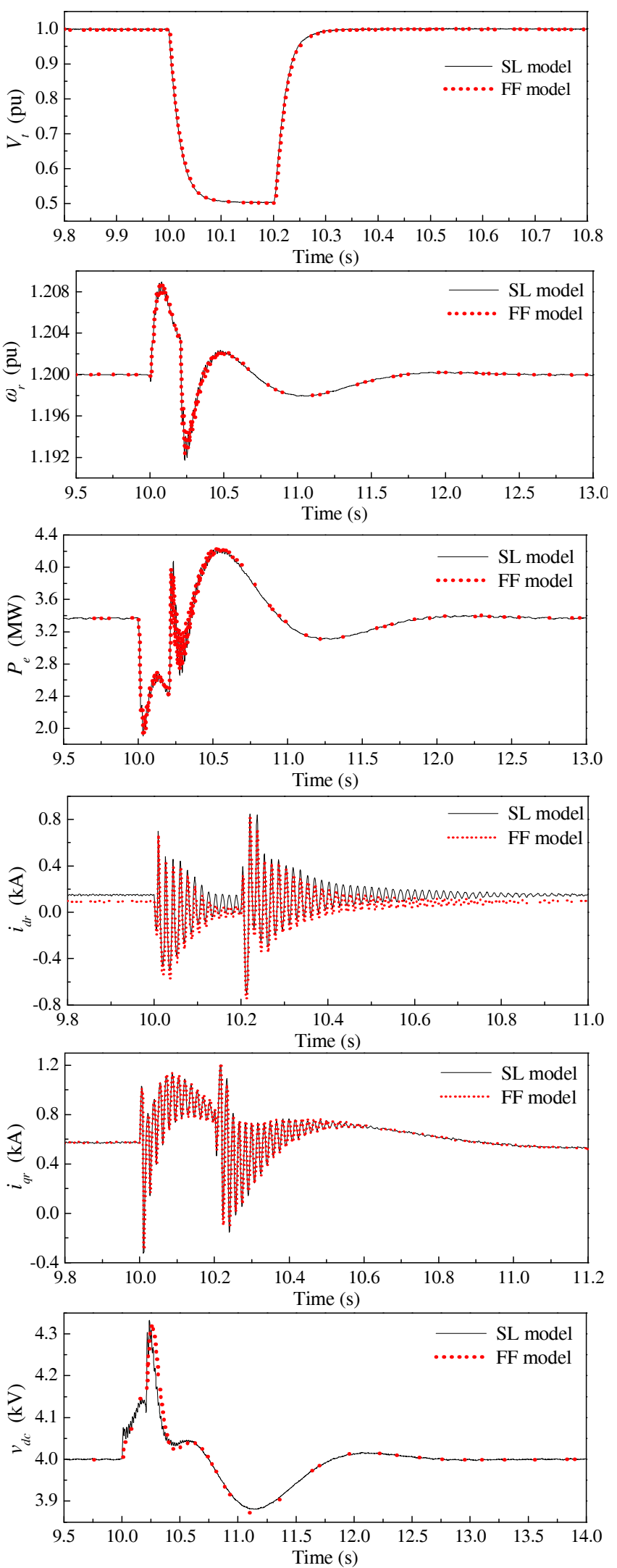

Fig. 9. A $200 \mathrm{~ms}$ three-phase short circuit: network voltage $V_{t}$, DFIG rotor speed $\omega_{r}$, output power $P_{e}$, rotor currents $i_{d r}$ and $i_{q r}$, and dc-link voltage $v_{d c}$.

\section{A. Case I: DFIG Acceleration through Synchronous Speed}

The DFIG initially operates with the rotor speed at $\omega_{r}=0.9$ pu. From $10 \mathrm{~s}$, the speed command $\omega_{r}^{*}$ is gradually increased from 0.9 pu to $1.2 \mathrm{pu}$ in 5 seconds. During the entire test, the wind speed is assumed to be constant. Fig. 8 compares the results of the DFIG rotor speed $\omega_{r}$ and rotor phase current $i_{r a}$ when using the SL model and the FF model. The two models provide the same results and a smooth transition of the rotor currents from subsynchronous to supersynchronous modes.

\section{B. Case II: Three-Phase Short Circuit Test at the Infinite Bus}

A $200 \mathrm{~ms}$ three-phase short circuit is applied to the infinite bus at $t=10 \mathrm{~s}$. Fig. 9 shows the results of the network voltage $V_{t}$, DFIG rotor speed $\omega_{r}$, output active power $P_{e}$, rotor currents $i_{d r}$ and $i_{q r}$, and dc-link voltage $v_{d c}$. This fault causes a voltage sag in $V_{t}$ at the grid connection point of the WTG. This sag results in an imbalance between the turbine input power and the DFIG output power and therefore a high current in the DFIG stator windings. Because of the magnetic coupling between stator and rotor, this current also flows in the rotor circuit and the converter. Due to the stator flux oscillations during this transient state, the rotor currents oscillate with a frequency near the synchronous frequency [2], as can be seen from the waveforms of $i_{d r}$ and $i_{q r}$. These results show that the simplified FF model provides the same model accuracy as the SL model, even for this severe disturbance.

\section{Case III: Step Change in Wind Speed}

The wind speed is assumed to change from $11 \mathrm{~m} / \mathrm{s}$ to 14 $\mathrm{m} / \mathrm{s}$ at $t=10 \mathrm{~s}$. In this case, the pitch angle controller is activated to increase the blade pitch angle to shed some part of the wind power. The turbine pitch angle $\beta$, DFIG rotor speed $\omega_{r}$, output active power $P_{e}$, rotor currents $i_{d r}$ and $i_{q r}$, and dc-link voltage $v_{d c}$ are compared in Fig. 10 for the SL and FF models. The pitch angle changes from $0^{\circ}$ to about $8^{\circ}$ to prevent the WTG from overloading in such a strong wind. As a result, the DFIG rotor speed $\omega_{r}$ and the output active power $P_{e}$ are controlled at their rated values of $1.2 \mathrm{pu}$ and $3.6 \mathrm{MW}$, respectively, after the system returns to the steady state condition. The same level of accuracy is achieved by using the two different models.

\section{Case IV: Effect of Speed Controller PI Gains When Using Two-Mass Shaft Model}

Based on the results in Sections IV-A, B and C, the FF model is accurate enough for modeling the DFIG and its VFC, and therefore, is used for further simulation studies. During the rest simulation study, the turibne pitch angle and the DFIG speed reference are set at $7.5^{\circ}$ and $1.2 \mathrm{pu}$, respectively.

Grid disturbances may excite shaft torsional oscillations, primarily, in the shaft system equipped a gearbox. These torsional oscillations can be seen in the fluctuations of the generator rotor speed as well as the electrical parameters of the generator, such as the electrical power and rotor current. When the torsional oscillations are insufficiently damped, the WTG might have to be disconnected. As discussed in Section III-A, in order to damp the low-frequency torsional oscillations, the gain and bandwidth of the DFIG speed controller must be properly designed.

Assuming that the wind speed is step changed from $10 \mathrm{~m} / \mathrm{s}$ to $13.5 \mathrm{~m} / \mathrm{s}$ at $t=10 \mathrm{~s}$, Fig. 11 shows the responses of the DFIG output active power $P_{e}$ when using different integral 
gains, where $k_{i 1}<k_{i 2}<k_{i 3}<k_{i 4}\left(k_{i 1}=0.1, k_{i 2}=0.2, k_{i 3}=1.0\right.$, and $\left.k_{i 4}=4.0\right)$. A larger integral gain yields a higher bandwidth for the closed-loop system. These results indicate that the smallest gain $k_{i 1}$ should be used. It provides the closed-loop system with a sufficient low bandwidth so that the lowfrequency torsional oscillations are sufficiently damped.
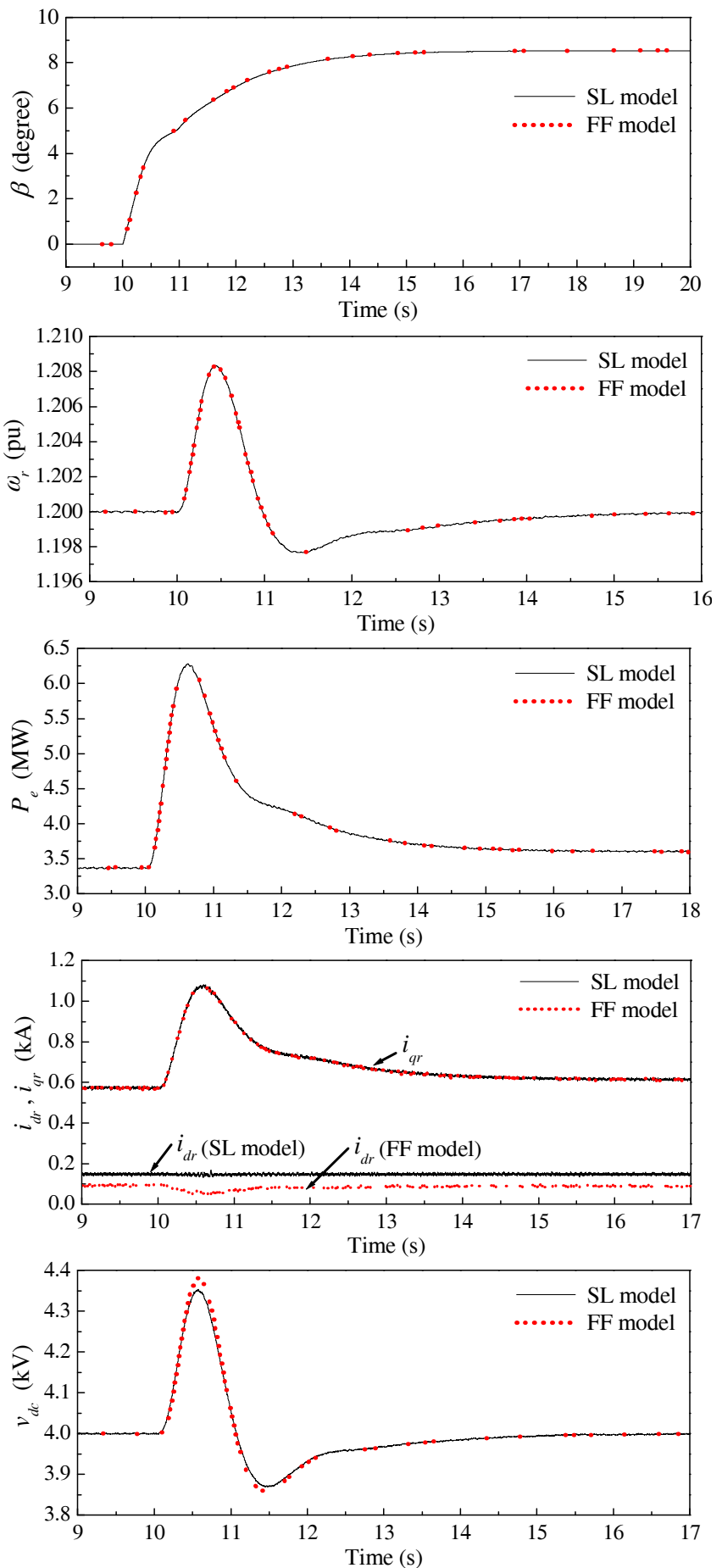

Fig. 10. Test during strong wind: blade pitch angle $\beta$, DFIG rotor speed $\omega_{r}$, output active power $P_{e}$, rotor currents $i_{d r}$ and $i_{q r}$, and dc-link voltage $v_{d c}$.

Now the integral gain is fixed at $k_{i}=0.1$. The same step change as in Fig. 11 is applied to the wind speed at $t=10 \mathrm{~s}$. Fig. 12 shows the responses of $P_{e}$ when using different proportional gains for the speed controller, where $k_{p 1}<k_{p 2}<$ $k_{p 3}<k_{p 4}\left(k_{p 1}=0.01, k_{p 2}=0.04, k_{p 3}=0.1\right.$, and $\left.k_{p 4}=0.5\right)$. The best damping is achieved by using the gain $k_{p 3}$.

Fig. 13 shows the results of using different pairs of PI gains for the same tests in Figs. 11 and 12, where $k_{p 1}<k_{p 2}<k_{p 3}<k_{p 4}$, $k_{i 1}<k_{i 2}<k_{i 3}<k_{i 4}\left(k_{i 1}=0.1, k_{i 2}=0.2, k_{i 3}=1.0\right.$, and $\left.k_{i 4}=4.0\right)$, and the ratio $k_{p n} / k_{\text {in }}(n=1,2,3,4)$ is constant. The dynamic performance of the WTG system degrades with the increase of the PI gains. The smallest pair of PI gains $k_{p 1}$ and $k_{i 1}$ provides the best damping performance, which are the same as those chosen from the previous tests in Figs. 11 and 12

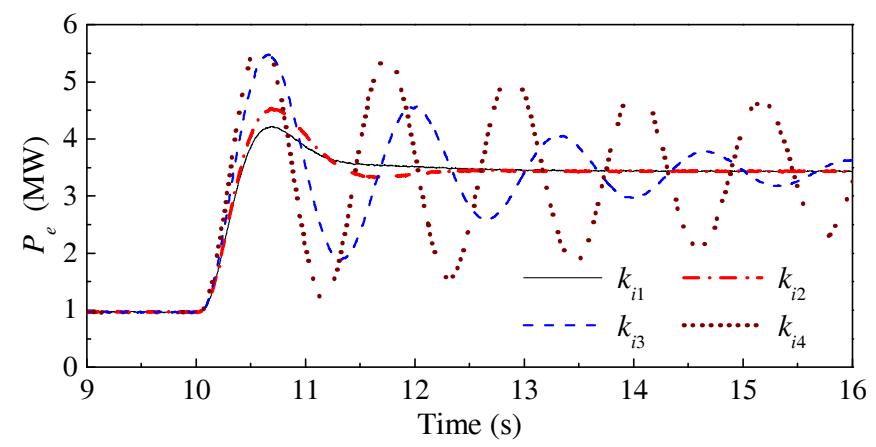

Fig. 11. Effect of the speed controller integral gain $\left(k_{i 1}<k_{i 2}<k_{i 3}<k_{i 4}\right)$ when using the two-mass shaft model: DFIG output active power $P_{e}$.

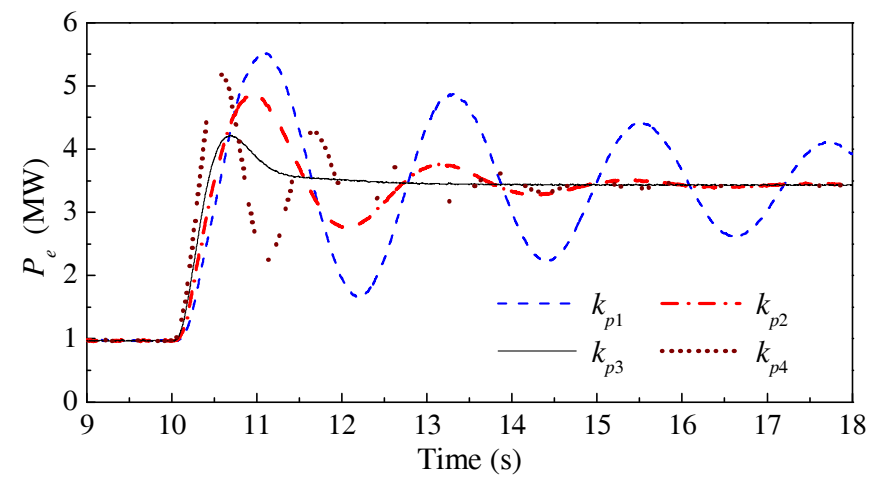

Fig. 12. Effect of the speed controller proportional gain $\left(k_{p 1}<k_{p 2}<k_{p 3}<k_{p 4}\right)$ when using the two-mass shaft model: DFIG output active power $P_{e}$.

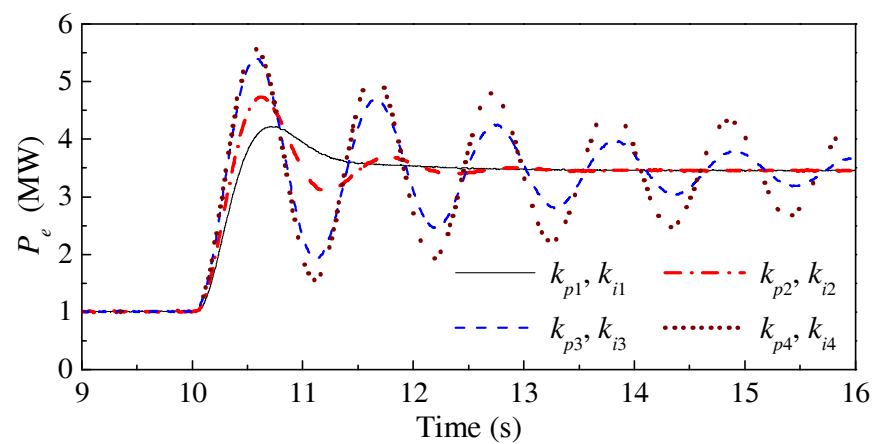

Fig. 13. Effect of the speed controller PI gains $\left(k_{p 1}<k_{p 2}<k_{p 3}<k_{p 4}, k_{i 1}<k_{i 2}<k_{i 3}<\right.$ $k_{i 4}$, and the ratio $k_{p n} / k_{\text {in }}$ is constant for $\left.n=1,2,3,4\right)$ when using the two-mass shaft model: DFIG output active power $P_{e}$.

\section{E. Case V: Effect of Speed Controller PI Gains When Using Lumped-Mass Shaft Model}

The same PI gains and tests as used for the two-mass shaft system in Fig. 13 are now used for the lumped-mass shaft system and the results are shown in Fig. 14. These results 
indicate that the lumped-mass shaft model provides the WTG system with a different dynamic behavior from the two-mass shaft model. As shown in Fig. 14, there are no low-frequency oscillations when using any pairs of PI gains, and therefore, the speed controller can be designed with a higher bandwidth by using the largest PI gains $k_{p 4}$ and $k_{i 4}$. This pair of PI gains however causes large oscillations in the DFIG output active power $P_{e}$, when using the two-mass shaft model, as shown in Fig. 14. Therefore, the lumped-mass model is not sufficient to represent the dynamic behavior of the WTG system and provides a wrong model for designing the WTG controllers.

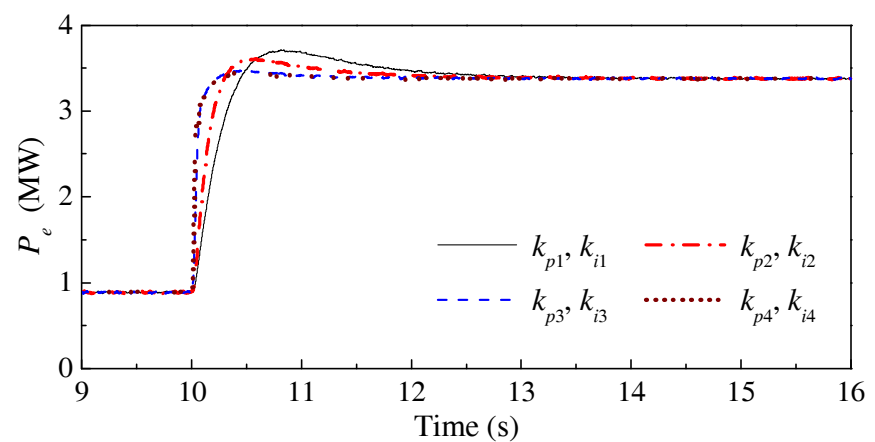

Fig. 14. Effect of the speed controller PI gains $\left(k_{p 1}<k_{p 2}<k_{p 3}<k_{p 4}, k_{i 1}<k_{i 2}<k_{i 3}<\right.$ $k_{i 4}$, and the ratio $k_{p n} / k_{i n}$ is constant for $\left.n=1,2,3,4\right)$ when using the lumpedmass shaft model: DFIG output active power $P_{e}$.

\section{CONCLUSION}

Two different models have been presented and developed in PSCAD/EMTDC to represent a wind turbine equipped with a doubly fed induction generator (DFIG). One is a detailed switching-level (SL) model, in which the variable frequency converter (VFC) is fully represented by individual IGBT switches and a dc-link capacitor. The other is a simplified fundamental-frequency (FF) model, in which the VFC is represented by two current-controlled voltage sources which take into account the dc-link dynamics. The other parts of the wind turbine generator (WTG) system, including the wind turbine, shaft system, induction generator, DFIG controller and pitch angle controller, have been modeled or designed in the same level of detail for both models. Simulation studies have been carried out for a 3.6 MW DFIG wind turbine using both the SL model and the FF model, and taking into account different shaft system representations. Results have shown that the SL and FF models provide the same level of accuracy. Therefore, the FF model should be used in order to speed up the simulation process of the power system equipped with DFIG wind turbines.

Moreover, the effect of different shaft system models (twomass or lumped-mass) on the dynamic behavior and control of the WTG has been investigated based on both analytical and transient simulation studies. When using the lumped-mass model, the WTG does not exhibit any low-frequency torsional oscillations that exist in the practical system and in the twomass shaft model. Therefore, the two-mass shaft model should be used for the study of power system transient dynamics. The torsional oscillations can be sufficiently damped by using a suitably designed DFIG speed controller.

\section{APPENDIX}

Wind turbine: rated capacity $=3.6 \mathrm{MW}$, number of blades $=3$, rotor diameter $=104 \mathrm{~m}$, swept area $=8495 \mathrm{~m}^{2}$, rotor speed $($ variable $)=8.5-15.3 \mathrm{rpm}$.

Mechanical shaft system (base power $=3.6 \mathrm{MW}): H_{t}=$ $4.29 \mathrm{~s}, H_{g}=0.9 \mathrm{~s}, D_{t}=D_{g}=0, D_{t g}=1.5 \mathrm{pu}, K_{t g}=296.7 \mathrm{pu}$.

Wound-rotor induction generator: rated power $=3.6 \mathrm{MW}$, rated stator voltage $=4.16 \mathrm{kV}$, power factor $p f=-0.9 \sim+0.9$, $r_{s}=0.0079 \mathrm{pu}, r_{r}=0.025 \mathrm{pu}, r_{m}=66.57 \mathrm{pu}, L_{l s}=0.07937 \mathrm{pu}$, $L_{l r}=0.40 \mathrm{pu}, L_{m}=4.4 \mathrm{pu}$, base frequency $f=60 \mathrm{~Hz}$.

Power network in Fig. 7 (base power $=3.6 \mathrm{MVA}$, base voltage $=34.5 \mathrm{kV}): r_{l 1}=r_{l 2}=0.014 \mathrm{pu}, x_{l 1}=x_{l 2}=0.08 \mathrm{pu}$, constant impedance load $Z_{L}=2.6+j 1.5 \mathrm{pu}$.

\section{REFERENCES}

[1] R. Datta and V. T. Ranganathan, "Variable-speed wind power generation using doubly fed wound rotor induction - a comparison with alternative schemes,' IEEE Trans. Energy Conversion, vol. 17, no. 3, pp. 414-421, Sept. 2002.

[2] V. Akhmatov, "Analysis of Dynamic Behavior of Electric Power Systems with Large Amount of Wind Power," Ph.D. dissertation, Technical University of Denmark, Kgs. Lyngby, Denmark, Apr. 2003.

[3] M. V. A. Nunes, J. A. Pecas Lopes, H. H. Zurn, U. H. Bezerra, and R. G. Almeida, "Influence of the variable-speed wind generators in transient stability margin of the conventional generators integrated in electrical grids," IEEE Trans. Energy Conversion, vol. 19, no. 4, pp. 692-701, Dec. 2004.

[4] J. Morren and S. W. H. de Haan, "Ridethrough of wind turbines with doubly-fed induction generator during voltage dip," IEEE Trans. Energy Conversion, vol. 20, no. 2, pp. 435-441, Jun. 2005.

[5] Y. Lei, A. Mullane, G. Lightbody, and R. Yacamini, "Modeling of the wind turbine with a doubly fed induction generator for grid integration studies," IEEE Trans. Energy Conversion, vol. 21, no. 1, pp. 257-264, Mar. 2006.

[6] T. Petru and T. Thiringer, "Modeling of wind turbines for power system studies," IEEE. Trans. Power Systems, vol. 17, no. 4, Nov. 2002, pp. 144151.

[7] J. G. Slootweg, S. W. H. de Hann, H. Polinder, and W. L. Kling, "General model for representing variable speed wind turbines in power system dynamic simulations," IEEE. Trans. Power Systems, vol. 18, no. 1, pp. 1132-1139, Feb. 2003

[8] A. Tapia, G. Tapia, J. X. Ostolaza, and J. R. Saenz, "Modeling and control of a wind turbine driven doubly fed induction generator," IEEE Trans. Energy Conversion, vol. 18, no. 2, pp. 194-204, Jun. 2003.

[9] P. Ledesma and J. Usaola, "Doubly fed induction generator model for transient stability analysis," IEEE Trans. Energy Conversion, vol. 20, no. 2, pp. 388-397, June 2005.

[10] J. B. Ekanayake, L. Holdsworth, X. G. Wu, and N. Jenkins, "Dynamic modeling of doubly fed induction generator wind turbines," IEEE Trans. Power Systems, vol. 18, no. 2, pp. 803-809, May 2003.

[11] W. Qiao, W. Zhou, J. M. Aller, and R. G. Harley, "Wind speed estimation based sensorless output maximization control for a wind turbine driving a DFIG," IEEE Trans. Power Electronics, vol. 23, no. 3, pp. 1156-1169, May 2008.

[12] N. W. Miller, W. W. Price, and J. J. Sanchez-Gasca, "Dynamic modeling of GE 1.5 and 3.6 wind turbine-generators," GE-Power Systems Energy Consulting, General Electric International, Inc., Schenectady, NY, USA, Oct. 27, 2003.

[13] S. K. Salman and A. L. J. Teo, "Windmill modeling consideration and factors influencing the stability of a grid-connected wind power-based embedded generator," IEEE Trans. Power Systems, vol. 18, no. 2, pp. 793-802, May 2003.

[14] D. W. Novotny and T. A. Lipo, Vector Control and Dynamics of AC Drives, Oxford University Press, 2000.

[15] G. Ellis, R. D. Lorenz, "Resonant load control method for industrial servo drives," in Proc. IEEE Industry Applications Conference, Oct. 8-12, 2000, pp. 1438-1445. 